\title{
Numerical and Experimental Study on the Grinding Performance of Ti-Based Super-Alloy
}

\author{
Hung Trong Phi ${ }^{1,2}$, Got Van Hoang ${ }^{3}$, Trung Kien Nguyen ${ }^{2}$, Son Hoanh Truong ${ }^{2, *}$ \\ ${ }^{1}$ Mechanical and Power Engineering Faculty, Electric Power University, Hanoi, Vietnam \\ ${ }^{2}$ School of Mechanical Engineering, Hanoi University of Science and Technology, Hanoi, Vietnam \\ ${ }^{3}$ Vietnam National Research Institute of Mechanical Engineering, Hanoi, Vietnam \\ Received 22 February 2021; received in revised form 06 April 2021; accepted 08 April 2021
}

DOI: https://doi.org/10.46604/ijeti.2021.7199

\begin{abstract}
The experiments of the surface grinding of Ti-6Al-4V grade 5 alloy (Ti-64) with a resin-bonded cubic Boron Nitride (cBN) grinding wheel are performed in this research to estimate the influence of cutting parameters named workpiece infeed speed, Depth of Cut (DOC), cooling condition on the grinding force, force ratio, and specific energy. A finite element simulation model of single-grain grinding of Ti-64 is also implemented in order to predict the values of grinding forces and temperature. The experimental results show that an increase of workpiece infeed speed creates higher intensified cutting forces than the DOC. The grinding experiments under wet conditions present slightly lower tangential forces, force ratio, and specific energy than those in dry grinding. The simulation outcomes exhibit that the relative deviation of simulated and experimental forces is in the range of 1-15\%. The increase in feed rate considerably reduces grinding temperature, while enhancement of DOC elevates the heat generation in the cutting zone.
\end{abstract}

Keywords: grinding, titanium alloy, grinding force, grinding temperature, finite element simulation

\section{Introduction}

Grinding is a very complicated cutting process due to the great number of abrasive grains with large negative rake angles participating in the metal removal operation. If the cutting parameters are not properly chosen, this process can be even more difficult. Inadequate cutting conditions can result in the creation of surface failures such as thermal burn, tensile residual stress, debris adherence, and rapid tool wear, etc. Together with selecting adequate grinding conditions, the employment of cutting fluid is also an effective strategy to enhance grinding performance [1]. With the introduction of enough cooling and lubricating activity, heat formation in the interaction region and thermal failure can be depressed. Meanwhile, dry grinding sometimes exhibits useful impacts, i.e. lowering thermal shock, reducing environmental effect, improving surface morphology, etc.

Titanium alloys have a high strength-to-weight ratio, excellent corrosion resistance, and superior strength at elevated temperature, thereby they are used in a wide range of applications, such as the aerospace industry and biomedical field. However, those alloys are categorized as hard-to-machine materials because of the very short tool life and poor surface finish characteristics. To the grinding wheel, cubic Boron Nitride (cBN) abrasive is an attractive choice for machining difficult-to-cut material because of high cutting capacity and less thermal failure. Additionally, resin-bonded cBN wheels are usually used as

* Corresponding author. E-mail address: son.truonghoanh@ @ust.edu.vn Tel.: +84-904241165 
it can obtain high surface quality and possesses good impact strength [2]. An internal evolved porous composite-bonded cBN wheel with graphene nanoplatelets was investigated by Chen et al. [3]. It was seen that adding graphene could keep the sharpness of the abrasives at some range and maintain the self-sharpening capacity of the grinding wheel. Hence, the graphene-added porous composite-bonded cBN wheel could achieve high efficiency and favorable surface quality as grinding of Ti-64 alloy. An induction of brazed formed monolayer cBN wheel was utilized for the grinding of a dovetail slot made from Ti-64 alloy in the study of $\mathrm{Li}$ et al. [4]. By comparison with the electroplated wheel, the brazed tool exhibited superior performance, i.e. the lower specific cutting energy and the better workpiece surface. The study of Naskar et al. [5] evaluated the wear process of the electroplated cBN wheel and its effectiveness on the machinability of Ti-6Al-4V under various cooling and lubricating environments and high grinding speeds. It was found that thermal-shock-induced breakage was the main reason for wheel wear, and water-based fluids showed 2 to 4 times more wear than neat oil. Zhao et al. [6] implemented single-grit grinding experiments of Ti-64 alloy to estimate the grinding performance of sintered Aggregated cubic Boron Nitride (AcBN) grits. The outcomes indicated that AcBN grains obtained a more steady grinding force ratio, higher material removal rate, and more stable wear areas than common monocrystalline cBN ones.

In the grinding operation of Ti-64, surface burn and oxidation usually occur due to large heat generation, which considerably results in poor surface performance. On the other hand, excessively high temperature in the contact zone also leads to undesirable tensile residual stress and voids [7]. Hence, the prediction of cutting temperature is very necessary for the grinding process for Ti-64 alloy, which would contribute to the optimization of cutting conditions, reduction of grinding temperature, and improvement of surface quality [8]. Besides experimental studies, many numerical cutting simulations are performed on the grinding of Ti-64 alloy. Particularly, numerous researchers have recently investigated the grinding process using Finite Element Method (FEM). This is an efficient tool to study the cutting processes which provides valuable knowledge on the material removal process, cutting temperature and forces, strain and stress as well.

Handa et al. [9] made a comparison between discrete fragmented grinding and common continuous grinding using a 3D finite element simulation in ABAQUS/Explicit. The discrete-fragmented machining showed its capacity for keeping the cutting temperature under the critical value which avoided burning spots on the Ti-64 surface, and decreasing grinding force appreciably. The FEM simulation model of abrasive belt grinding was performed by Song et al. [10] to completely evaluate the change properties of thermal-mechanical constraints in the grinding process. The simulation outcomes exhibited that the ductile deformation region and dead metal region are suitable with the grinding theory. In the study of Yun et al. [11], a model of residual stress on the abrasive belt surface in the grinding process of TC17 titanium alloy was introduced based on the theory of molecular system dynamics. With a grinding speed of 8-24 m/s and feed rate of 20-60 m/min, the residual stress of the belt surface was - 169 to $-254 \mathrm{MPa}$, and the relative error between simulation and experiment was below $20 \%$. In the study of Liu et al. [12], a FEM simulation was employed for analyzing the high-speed grinding of PTMCs alloy using a monolayer brazed cBN wheel. Under the investigated grinding parameters, the undeformed chip thickness had a larger effect on the defect formation of the machined surface than the grinding speed did. The simulated outcomes were highly compatible with experimental ones.

This study is conducted to improve the performance of the grinding process on Ti-64 grade 5. Influences of cutting conditions, including workpiece infeed speed, Depth of Cut (DOC), cooling environment on the grinding force, force ratio, and specific energy are studied. Based on FEM, this work also predicts the grinding forces and cutting temperature in the single-grain grinding of Ti-64 alloy using ABAQUS/Explicit software. The explicit approach is used as it can solve dynamic balance problems of solid mechanics, in other words, it is founded on energy balance [13]. The simulation results can be employed to understand the material removal process and to select the cutting and lubricating conditions in the grinding of Ti-64 alloy. 


\section{Grinding Simulation and Experiments}

\subsection{Experimental work}

The grinding experiments are performed on a high-speed vertical machining center (HS Super MC500, Fuhong Machinery Co., Taiwan), as demonstrated in Fig. 1. The diameter and grit size of the cBN wheel is $100 \mathrm{~mm}$ and \#120, respectively. The dimension of the annealed Ti-64 grade 5 specimens is $16 \times 10 \times 9 \mathrm{~mm}$, with a cutting width of $4.5 \mathrm{~mm}$ and a cutting length per pass of $16 \mathrm{~mm}$. The mechanical and thermal properties of the Ti-64 alloy and cBN grit are presented in Table 1. Plunge up-grinding mode is utilized in all experiments with wheel revolution constantly at 5733 rpm (cutting speed of 30 $\mathrm{m} / \mathrm{s})$. A total number of 24 tests are performed following the cutting variables detailed in Table 2 . The table speed $v_{w}$ is $1,3,6$, and $10 \mathrm{~m} / \mathrm{min}$, and DOC is 5, 10, and $15 \mu \mathrm{m}$, under dry and wet environments. In wet grinding conditions, a synthetic oil-based fluid including oil concentration at $2 \mathrm{vol} \%$ is provided at a flow rate of $30 \mathrm{l} / \mathrm{min}$ through two cooling nozzles. In the cutting process, the sample is clamped in a fixture combined with a three-component piezoelectric dynamometer (No. 9139AA, KISTLER Instrument), which provided the normal and tangential force measurement. The force sensor is connected to an Analog-to-Digital (A/D) converter, then the data are processed and recorded by a data acquisition system. The vibration of the main spindle is monitored using a Triaxial DeltaTron Accelerometer (Brüel \& Kjær, Denmark).

Table 1 Material properties of Ti-64 alloy and cBN grit

\begin{tabular}{|c|c|c|c|c|c|c|}
\hline Material & $\begin{array}{c}\text { Young modulus, } \\
E(\mathrm{GPa})\end{array}$ & $\begin{array}{c}\text { Poisson's } \\
\text { ratio, } \mu\end{array}$ & $\begin{array}{c}\text { Density, } \rho \\
\left(\mathrm{kg} / \mathrm{m}^{3}\right)\end{array}$ & $\begin{array}{c}\text { Thermal conductivity } \\
\left(\mathrm{W} / \mathrm{m} \cdot{ }^{\circ} \mathrm{C}\right)\end{array}$ & $\begin{array}{c}\text { Specific Heat } \\
\left(\mathrm{J} / \mathrm{kg} \cdot{ }^{\circ} \mathrm{C}\right)\end{array}$ & Emissivity \\
\hline Ti-6Al-4V & 108 & 0.33 & 4440 & 6.6 & 580 & 0.4 \\
\hline $\mathrm{cBN}$ & 909 & 0.12 & 3120 & 240 & 670 & 0.4 \\
\hline
\end{tabular}

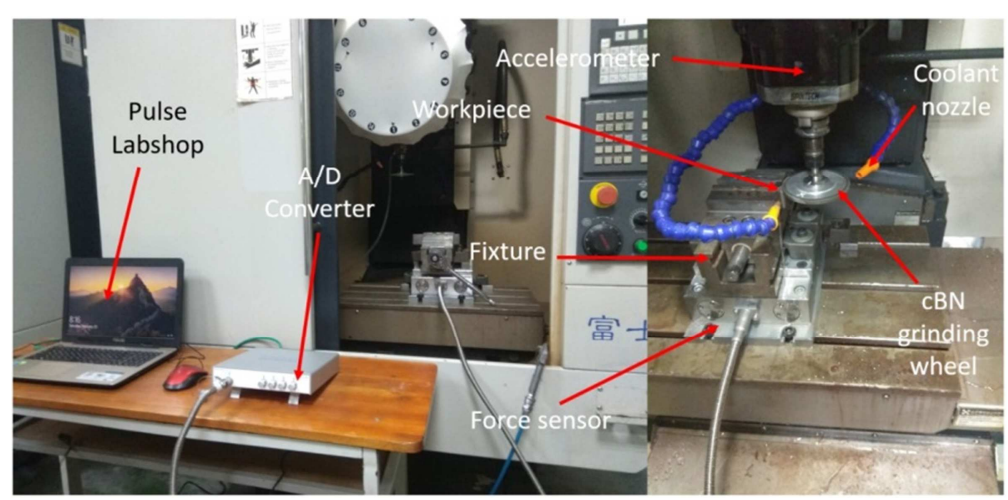

Fig. 1 The setup for the surface grinding experiments

Table 2 The cutting conditions of grinding experiments

\begin{tabular}{|c|c|}
\hline Grinding wheel & Resin-bonded cBN grinding wheel, \#120 \\
\hline External wheel diameter, $d_{s}$ & $100 \mathrm{~mm}$ \\
\hline Cutting velocity, $v_{c}$ & $30 \mathrm{~m} / \mathrm{s}$ \\
\hline Table speed, $v_{w}$ & $1,3,6,10 \mathrm{~m} / \mathrm{min}$ \\
\hline Depth of cut, $a_{p}$ & $5,10,15 \mu \mathrm{m}$ \\
\hline Grinding width, $b$ & $4.5 \mathrm{~mm}$ \\
\hline Environments & Dry and wet grinding $(2 \mathrm{vol} \%$ dilutions synthetic oil $)$ \\
\hline Dressing & Impregnated diamond dresser \\
\hline
\end{tabular}

\subsection{Finite element model of the grinding simulation}

The cutting temperatures at the griding zone which is a very important controlling parameter of the tool life and surface finish are not accurately captured by the experimental measurements. To forecast the grinding temperature in the interaction region, a two-dimensional (2D) finite element cutting model is applied, as shown in Fig. 2. The dimension of the Ti-64 
specimen is $310 \mu \mathrm{m}$ in length and $100 \mu \mathrm{m}$ in height (in the $\mathrm{X}$ and $\mathrm{Y}$ direction, respectively). The simulation is performed in ABAQUS/Explicit software using a Lagrangian algorithm. The Lagrangian formulation is principally utilized in solid mechanics. It permits the mesh and the matter displacing together, facilitating for monitoring surfaces and using boundary conditions. The Lagrangian formulation can simulate matter stream which consists of frictional heat and matter deformation although it requires complicated remeshing [13]. The meshing of the Ti-64 specimen is divided into 7750 bilinear four-node plane strain thermally coupled quadrilateral elements with reduced integration and enhanced hourglass control (CPE4RT). The abrasive is $\mathrm{cBN}$ grain modeled as half of the regular hexagon with a rake angle of $-30^{\circ}$, as indicated in Fig. 3. The cutting depth in the FEM model is set to be half of the maximum undeformed chip thickness $\left(a_{g m a x}\right)$ since the cutting depth of single grain always increases gradually until it reaches the value of $a_{g \max }$ in the general surface grinding process. The workpiece is fixed in the $\mathrm{X}$ and $\mathrm{Y}$ direction, while the $\mathrm{cBN}$ grain which is considered a rigid body moved at the same velocity as the cutting velocity, $v_{c}$. In the simulation for cutting temperature, the heat dissipation in the grinding wheel and the Ti-64 specimen are dominantly attributed by convection phenomenon with the convection coefficients of 81.148 and $82,000 \mathrm{~W} / \mathrm{m}^{2} . \mathrm{K}$ for the dry and wet grinding environment, respectively [8].

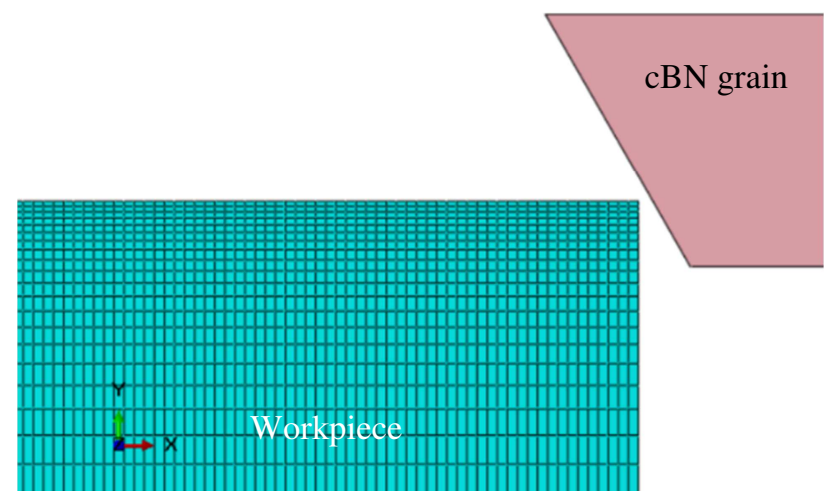

Fig. 2 The 2D FEM model for the grinding process with a single abrasive grain

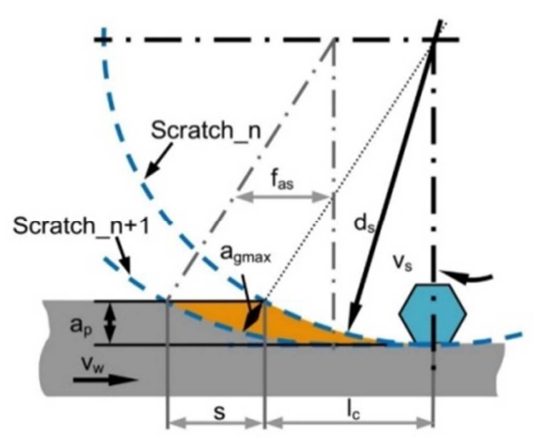

Fig. 3 Grinding operation of a single grain [14]

\subsubsection{Model of materials}

To give a better description of the Ti-64 properties under high temperature, large strain, and high strain rate during the grinding operation, the equation of Johnson-Cock plastic deformation model provided in [8] is used as shown in Eq. (1), where $\varepsilon$ is the equivalent flow strain; $\sigma$ is the equivalent flow stress; $\dot{\varepsilon}_{0}$ is reference plastic strain rate; $\dot{\varepsilon}$ is the equivalent plastic strain rate; $T$ is the sample temperature; $T_{m}$ and $T_{r}$ are the melting and room temperature, respectively. The mechanical and thermal properties of Ti-64 alloy and cBN grit used in the FEM model are presented in Table 1. The Johson-Cook parameters include five parameters which $A$ is the yield strength, $B$ is the hardening modulus, $C$ is the strain rate sensitively coefficient, $m$ is the thermal softening coefficient, and $n$ is the hardening coefficient. The J-C model parameters of Ti-64 alloy, shown in Table 3, are achieved from the torque test, static tensile test, and Split Hopkinson Pressure Bar (SHPB) test [15]. Since the cBN grit is considerably harder than the Ti-64 alloy, it can be counted as an analytical rigid body in the current analysis. 


$$
\sigma=\left(A+B \varepsilon^{n}\right)\left[1+C\left(\frac{\dot{\varepsilon}}{\dot{\varepsilon}_{0}}\right)\right]\left[1-\left(\frac{T-T_{r}}{T_{m}-T_{r}}\right)^{m}\right]
$$

Table 3 Johnson-Cook model constants of Ti-64 alloy

\begin{tabular}{|c|c|c|c|c|c|c|}
\hline$A /(\mathrm{MPa})$ & $B /(\mathrm{MPa})$ & $C$ & $N$ & $m$ & $T_{m}$ & $T_{r}$ \\
\hline 875 & 793 & 0.01 & 0.386 & 0.71 & 1560 & 20 \\
\hline
\end{tabular}

\subsubsection{Criterion of material failure}

The strain is used as an exclusive criterion in the material fracture criterion suggested by the Johnson-Cook model [16]. In the current study, the Johnson-Cook shear fracture criterion is employed. Since the equivalent plastic strain of an intact element is increased, the failure occurs when the failure parameter $w_{s}$ is larger than 1 . The variable $w_{s}$ is defined as Eq. (2), where $\Delta \varepsilon^{p l}$ is an increment of the equivalent plastic strain; $\varepsilon_{f}^{p l}$ is the failure strain and is calculated by Eq. (3) [16], where the failure strain is defined by the parameters $\sigma^{*}, \dot{\varepsilon}_{0}$, and $T$. $D_{1}$ to $D_{5}$ are the constants of the Johnson-Cook shear failure criterion. The Johnson-Cook shear failure constants $\left(D_{1}-D_{5}\right)$ of Ti-64 alloy are picked from the study of Fu [16] and presented in Table 4.

$$
\begin{aligned}
& \omega_{s}=\sum \frac{\Delta \varepsilon^{p l}}{\varepsilon_{f}^{p l}} \\
& \varepsilon_{f}^{p l}=\left(D_{1}+D_{2} e^{D_{3} \sigma^{*}}\right)\left[1+D_{4} \ln \frac{\dot{\varepsilon}^{p l}}{\dot{\varepsilon}_{0}}\right]\left[1-D_{5}\left(\frac{T-T_{r}}{T_{m}-T_{r}}\right)\right]
\end{aligned}
$$

Table 4 Johnson-Cook shear failure constants of Ti-64 alloy

\begin{tabular}{|c|c|c|c|c|c|}
\hline Material & $D_{1}$ & $D_{2}$ & $D_{3}$ & $D_{4}$ & $D_{5}$ \\
\hline Ti-64 & -0.09 & 0.25 & -0.5 & 0.014 & 3.87 \\
\hline
\end{tabular}

\subsubsection{Boundary conditions and the contacting properties}

In the grinding operation, the length of contact arc $\left(l_{\mathrm{c}}\right)$ between the Ti-64 specimen and the cBN grit presented in Fig. 3 is described by Eq. (4) [15], where $a_{p}$ is the cutting depth and $d_{s}$ denotes the outer diameter of the grinding wheel. From this calculation, the value of $l_{c}$ ranges from 0.71 to $1.23 \mathrm{~mm}$ in the current study, which is 2.5 to 4 times as large as the modeling length of the Ti-64 workpiece $(310 \mu \mathrm{m})$ in X-direction. Hence, the movement of the cBN grit in the X-axis can simply be considered a straight line in the cutting simulation model. Additionally, half of the maximum undeformed chip thickness $\left(a_{g m a x}\right)$ of the single abrasive grit is selected for the cutting depth in the simulation model instead of the actual DOC $a_{p}$ as calculation in Eq. (5), where $v_{w}$ is the table speed and $v_{c}$ is the cutting speed [15].

$$
\begin{aligned}
& l_{c}=\sqrt{d_{s} a_{p}} \\
& a_{g \max }=2 \pi d_{s} \frac{v_{w}}{v_{c}} \sqrt{\frac{a_{p}}{d_{s}}}
\end{aligned}
$$

During the metal cutting process, plastic deformation and friction induce thermal energy. Then, the change in the workpiece microstructure which affects cutting properties occurs as the excessively high temperature is presented in the cutting zone. In the cutting simulation, the friction between the $\mathrm{cBN}$ grit and the Ti-64 sample surface is expressed by the Coulomb's Law as shown in Eq. (6), where $\tau_{f}$ is the frictional stress, $\mu$ is the coefficient of friction, and $\sigma_{n}$ is the normal contact stress [17]. The friction coefficients can be calculated from the grinding force ratios obtained in the grinding tests [6] (the 
coefficients are 0.289 and 0.186 under dry and wet grinding conditions, respectively, in this study). ABAQUS/Explicit software also introduces an inelastic heat fraction, named the Taylor-Quinney empirical constant (often fixed to be 90\% [17]) to describe the percentage of plastic deformation energy transferred to heat in the machining process.

$$
\tau_{f}=\mu \sigma_{n}
$$

\section{Experimental and Simulation Results and Discussion}

\subsection{Experimental results}

\subsubsection{Influence of grinding parameters on grinding forces}

Fig. 4 presents the grinding forces under various cutting and cooling conditions. The experimental results show that the grinding forces increase sequentially as the cutting depth or workpiece infeed speed (table speed) ascends for all dry and wet cooling environments. At the DOC at $10 \mu \mathrm{m}$ under dry grinding, the normal force growth is up to $84 \%$ as the workpiece infeed speed varies between $1 \mathrm{~m} / \mathrm{min}$ and $10 \mathrm{~m} / \mathrm{min}$, while the gain of the tangential force is $88 \%$. On the other hand, as the workpiece infeed speed is constantly $3 \mathrm{~m} / \mathrm{min}$ (dry grinding), the increases of the normal and tangential force are $65 \%$ and $60 \%$, respectively, with DOC in the range of 5 to $15 \mu \mathrm{m}$. In accordance with the study of Li [18], the variation of the grinding forces can result from the change of maximum undeformed chip thickness.

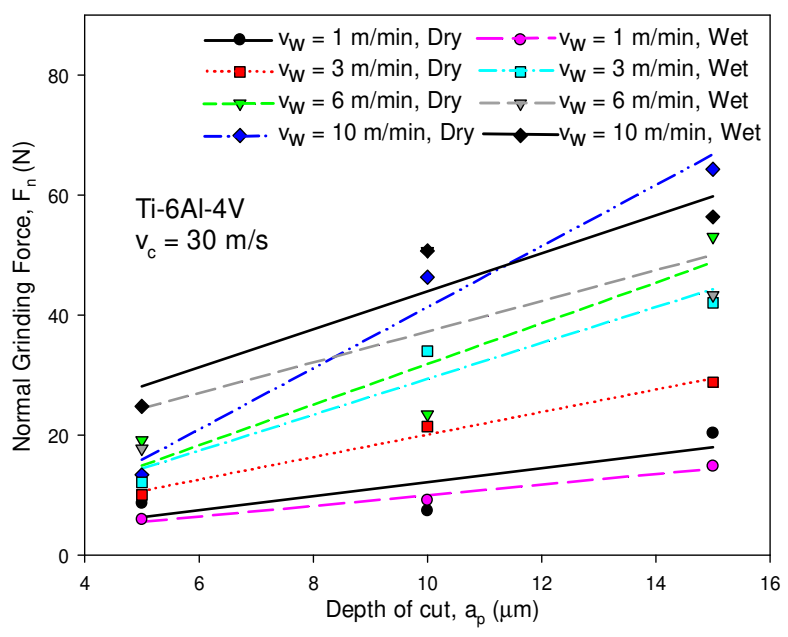

(a) Normal force vs. depth of cut

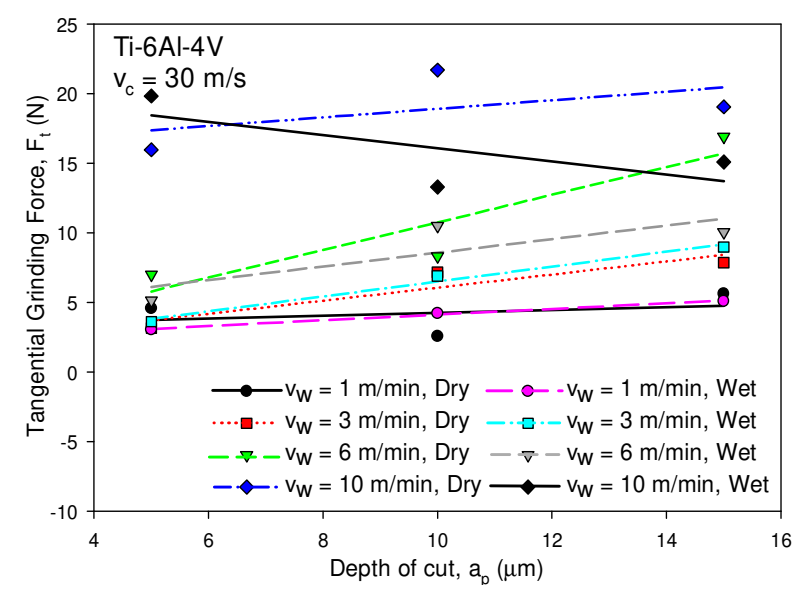

(c) Tangential force vs. depth of cut

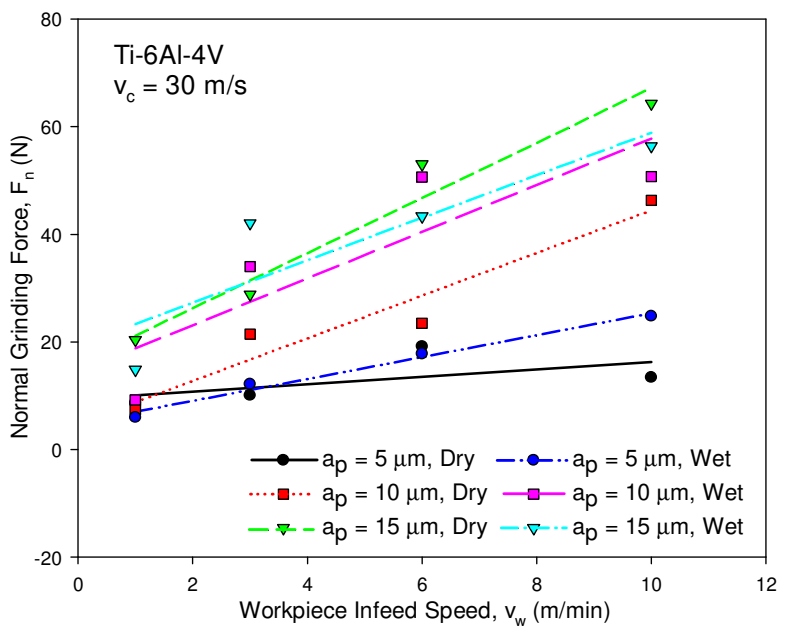

(b) Normal force vs. workpiece infeed speed

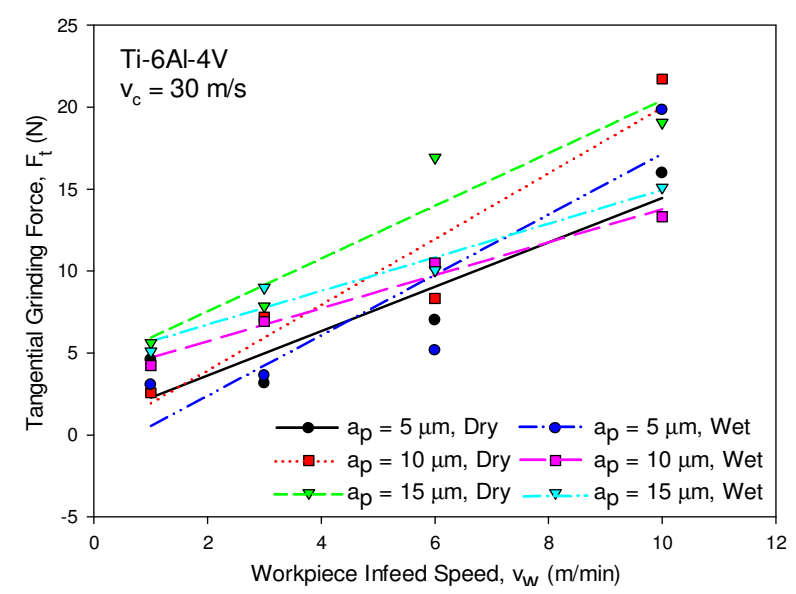

(d) Tangential force vs. workpiece infeed speed

Fig. 4 The influence of DOC and workpiece infeed speed on grinding forces at different cooling conditions 
Regarding cooling conditions, the tangential forces in the wet environment are generally lower in comparison with those in dry cutting conditions while slightly lower normal forces are found with dry grinding. In dry cutting conditions, the loads that occur on the $\mathrm{cBN}$ wheel surface are attributed to the adherence of debris to $\mathrm{cBN}$ grains at elevated temperatures due to the lack of cutting fluid. Then, the grit is blunt out quickly because of the work-hardening stress of the Ti-64 workpiece. Besides, less shearing and more rubbing activity of abrasive grains with debris adhesion all induce the force elevation [17]. In wet cutting conditions, the reduction of tangential force may result from lowered rubbing and ploughing action as the cooling-lubricating effect of cutting fluid removes the chips from the contact zone and reduce the wheel load [17, 19]. At a DOC of $10 \mu \mathrm{m}$ and a table speed of $6 \mathrm{~m} / \mathrm{min}$, there is a $21 \%$ reduction in the tangential force under the wet grinding compared to the dry cutting. The small difference in the tangential grinding force between these two cooling conditions can be from a relatively low concentration of cutting fluid (at 2 vol\%). From experimental data in Fig. 4, it also can be explicitly observed that normal forces always show about 3 times larger values than tangential forces, which can be predicted due to the high rubbing and ploughing activity of abrasive grains with a large negative rake angle [1].

The grinding force ratio is a key index indicating the friction condition at the contact zone between the workpiece and the wheel surface. The grinding force ratio is represented as Eq. (7) [20], where $\beta$ is the mean value of the peak semi-angle of abrasive grit. As seen in Eq. (7), although the grinding force ratio does not signify the frictional coefficient $\mu$, it is proportional to $\mu$.

$$
\frac{F_{t}}{F_{n}}=\frac{2}{\pi} \operatorname{Cot} \beta+\mu
$$

Fig. 5 shows that the force ratio in the dry environment is higher than those of the wet grinding because of more rubbing and ploughing action between the workpiece and wheel surface. In dry conditions, the excessively elevated temperature and the serious rubbing action happen due to the chemical reactions between $\mathrm{Ti}$ and $\mathrm{cBN}$ material. This results in ductile deformation and a discontinuous slide of the mating surfaces. The curve-fitting slope of force ratios for the dry and wet conditions are 0.289 and 0.186 , respectively. The utilization of synthetic oil fluid lowers the force ratio value, showing the smoother slipping of the participating surfaces [17]. In general, the force ratios at feed rate $v_{w}=10 \mathrm{~m} / \mathrm{min}$ with various DOCs are relatively high compared to their counterparts under other tested feed rates. At this high workpiece infeed speed, there is slight introduction of the main spindle's vibration, thereby the tangential force increases and waviness occurs onto the ground surface.

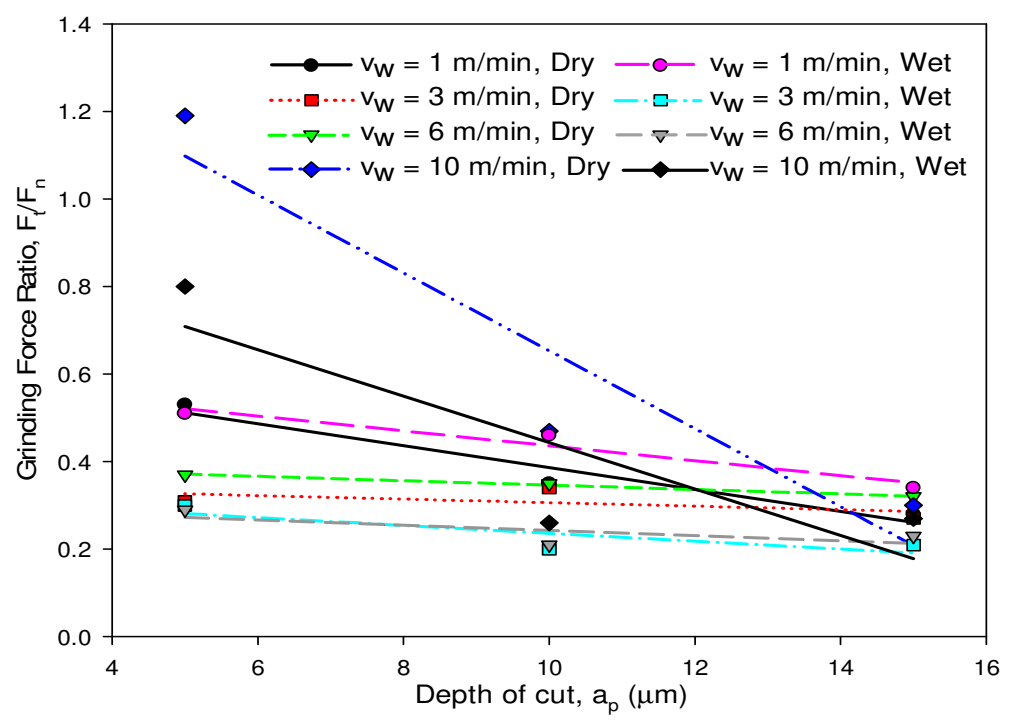

Fig. 5 The effect of DOC and $v_{w}$ on grinding force ratio $F_{t} / F_{n}$ at various cooling conditions 


\subsubsection{Influence of grinding parameters on specific energy}

Fig. 6(a) represents the relation between undeformed chip thickness $\left(a_{\text {gmax }}\right)$ and specific grinding energy $(u)$ in the grinding process of Ti-64 alloy. Specific grinding energy $u\left(\mathrm{~J} / \mathrm{mm}^{3}\right)$ is a significant factor of grindability in the machining operation exhibiting the required energy to remove one volume unit of workpiece material, which is described in Eq. (8) as a function of tangential force $F_{t}$, cutting velocity $v_{s}$, workpiece infeed speed $v_{w}$, cutting depth $a_{p}$, and grinding width $b$ [21]:

$$
u=\frac{F_{t} v_{s}}{v_{w} a_{p} b}
$$

The grinding specific energy of Ti-64 using a cBN wheel varies from 40 to $367 \mathrm{~J} / \mathrm{mm}^{3}$, which approves that this material is hard-to-grind [18]. Specific energy $u$ lowers when DOC increases, as seen in Fig. 6. The grinding operation of a single grain has three stages: sliding, ploughing, and chip creation, thereby the specific energy can also be separated into three elements: sliding, ploughing, and chip creation energy. During grinding operation, chip creation energy is the lowest necessary energy to remove specimen material so that it denotes the minimal value of $u$. The role of these three elements is different through the variation of DOC. At a large DOC, chip creation plays the primary role, and lower specific energy is observed [20]. The grinding energy quickly reduces with the growth of $a_{\text {gmax }}$ up to $5 \mu \mathrm{m}$, and thereafter slowly falls for all the cooling environments. With grinding at $v_{w}=3 \mathrm{~m} / \mathrm{min}$ and $a_{p}=10 \mu \mathrm{m}$, synthetic oil-based cooling provides a slight energy reduction of $4 \%$ in comparison with dry grinding. The slight difference in the grinding specific energy between these two cooling conditions is attributed to the relatively low concentration ( $2 \mathrm{vol} \%$ ) of cutting fluid. In dry cutting, the debris adhesion on the abrasive grains results in serious rubbing and ploughing action, which provides an inappreciable metal removal process, thereby enhances the specific energy [17]. Meanwhile, the lower grinding energy under a wet cooling environment is attributed to the lower tangential grinding forces, preservation of grain sharpness, and easy chip formation [19]. As shown in Fig. 6(b), the reduction of specific energy occurs along with the enhancement of the cross-section area of the cutting layer. The specific energy of a small cross-section is higher than that with a large cross-section. This suggests that a reduction in cross-section area will lead to a drop in tangential force $F_{t}$ which is not a considerable factor to lower specific energy [21].

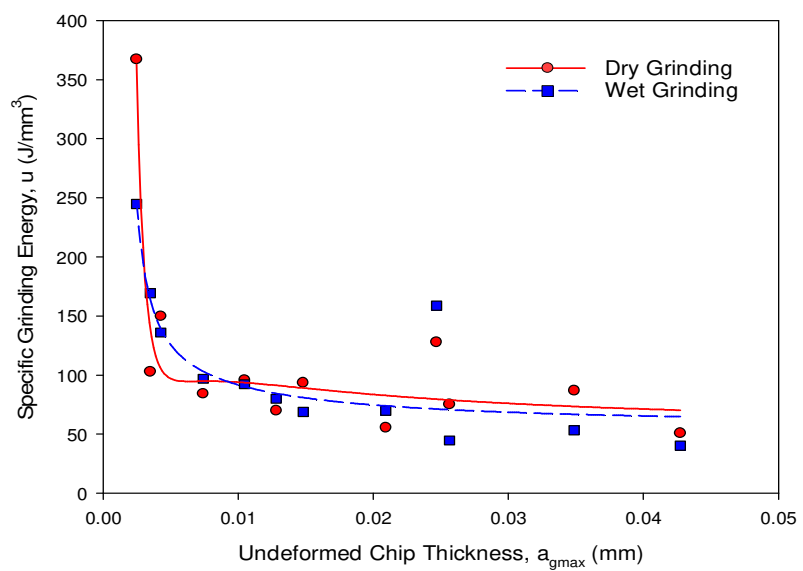

(a) Specific grinding energy vs. undeformed chip thickness

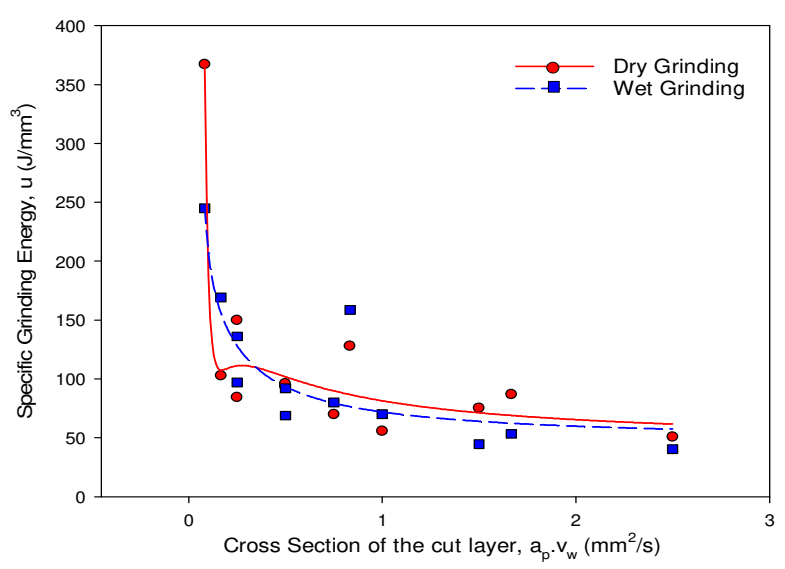

(b) Specific grinding energy vs. cross-section of cut layer

Fig. 6 The effect of undeformed chip thickness and cross-section of the cut layer on the specific grinding energy

\subsection{Simulation results}

\subsubsection{Chip formation process}

The rubbing, ploughing, and chip creation are the three main periods in the grinding operation. The analysis exhibits the three periods in the grinding of Ti-64 alloy using a single cBN abrasive grit, as indicated in Fig. 7. The rubbing period happens at a rather low DOC, which contains ductile deformation in the sample surface (Fig. 7(a)). With the enhancement of the cutting 
depth, the ploughing period begins, then ductile deformation happens and the sample surface slightly bloats (Fig. 7(b)). It can be realized that, under the rubbing and ploughing periods in the grinding process of a single grit, the sample material can not be rejected because DOC is lower than the critical thickness of chip creation. Eventually, since the DOC reaches the critical thickness of chip creation, a chip is induced and removed from the sample surface (Fig. 7(c)). Thus, it is discovered that there is a value called critical thickness of chip creation so that when the grit DOC is lower than that value, the grit only rubs and ploughs on the surface and will not create chips. Additionally, it is seen that the interrupted chips are formed in this grinding simulation. This process of chip formation is also verified in other reported studies [16].

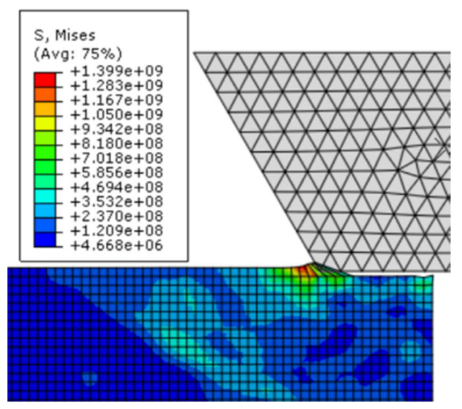

(a) Rubbing

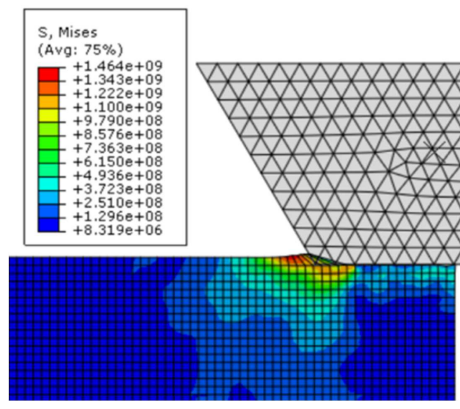

(b) Ploughing

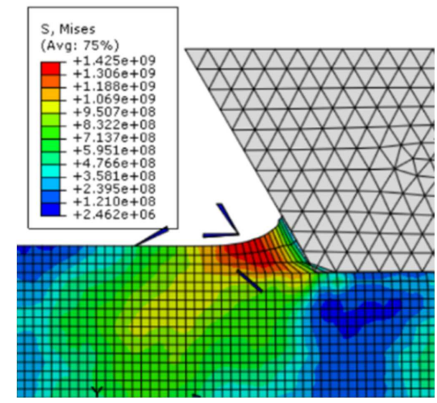

(c) Chip creation

Fig. 7 The simulation of three periods in the single-grain grinding process of Ti-64 alloy

\subsubsection{The validation of the simulated cutting forces with FEM}

The single-grain grinding forces $\left(f_{t}\right.$ and $\left.f_{n}\right)$ are the mean values of grinding force curves achieved with the FEM model. Then, the single-grain grinding normal force $f_{n}$ and tangential force $f_{t}$ obtained from finite element work are compared with the experimental results to check the validation of the FEM cutting model. The measurement of grinding force is performed under the cutting conditions described in Table 2 . The average values of experimental single-grain grinding forces $\left(f_{n}\right.$ and $\left.f_{t}\right)$ can be approximately defined as Eqs. (9) and (10) [22], where $F_{n}$ and $F_{t}$ are the experimental normal and tangential force, respectively; $b$ is the grinding width ( $4.5 \mathrm{~mm}$ at this study); $l_{c}$ is the length of contact arc between the wheel and sample surface; $N_{d}$ signifies the density of active grain, which is 12.5 grains $/ \mathrm{mm}^{2}$ evaluated from images of grinding wheel surface using an optical microscope.

$$
\begin{aligned}
& f_{n}=F_{n} / N_{d} b l_{c} \\
& f_{t}=F_{t} / N_{d} b l_{c}
\end{aligned}
$$

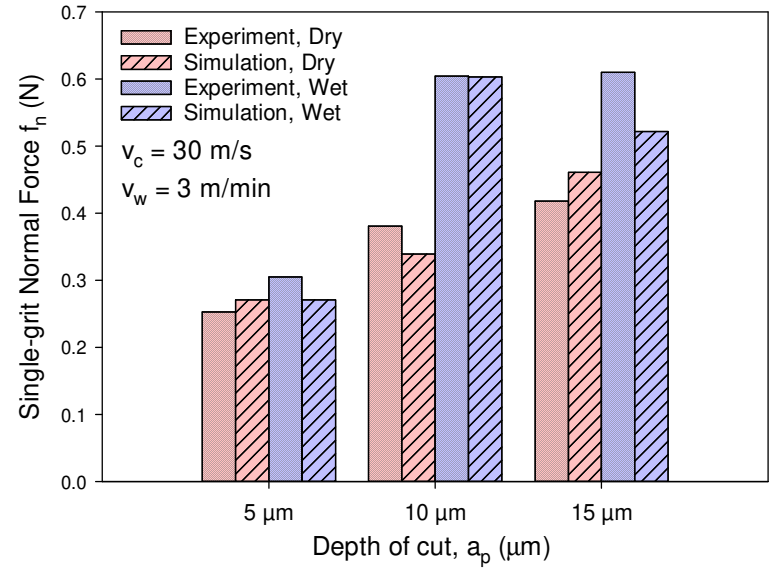

(a) Single-grit normal force vs. depth of cut

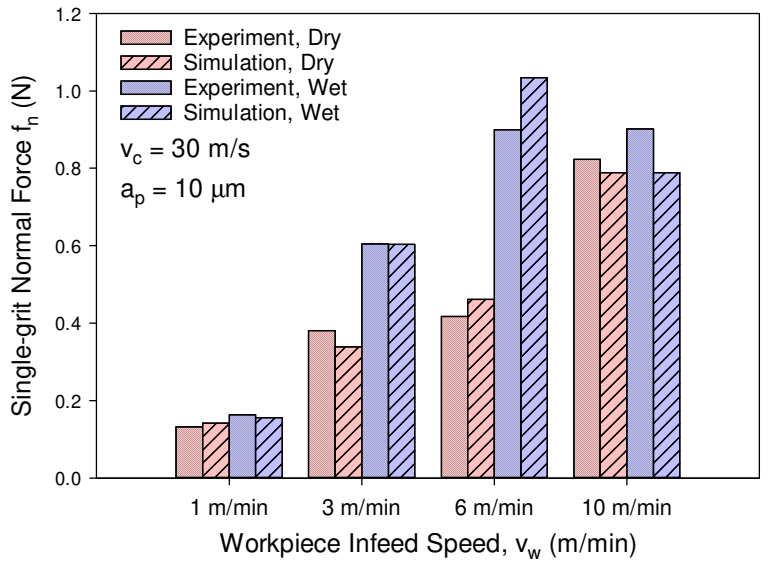

(b) Single-grit normal force vs. workpiece infeed speed

Fig. 8 The comparison of single-grit grinding forces between simulated and experimental results 


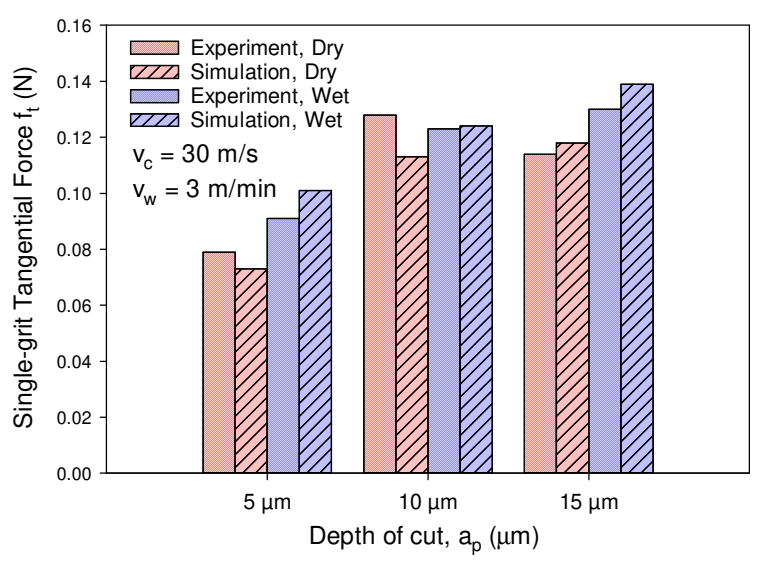

(c) Single-grit tangential force vs. depth of cut

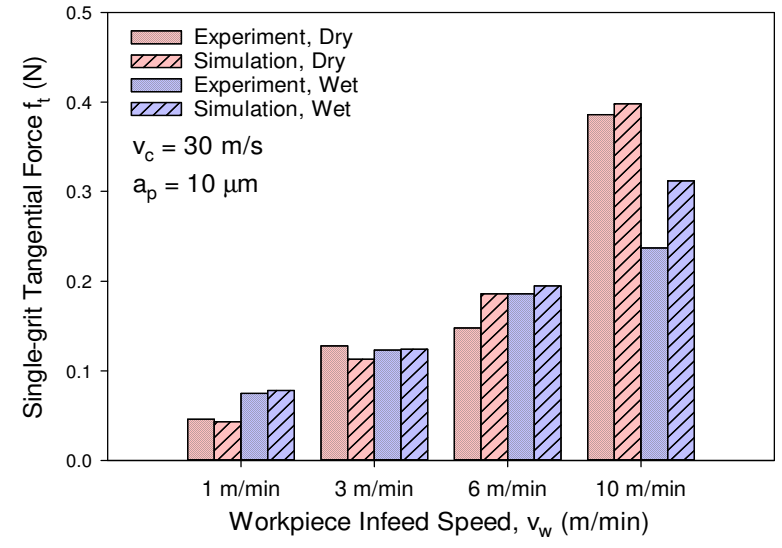

(d) Single-grit tangential force vs. workpiece infeed speed

Fig. 8 The comparison of single-grit grinding forces between simulated and experimental results (continued)

The experimental and predicted single-grain grinding forces in different grinding conditions (workpiece infeed speed $v_{w}$ at $1,3,6$, and $10 \mathrm{~m} / \mathrm{min}$, DOC $a_{p}$ at 5, 10, and $15 \mu \mathrm{m}$, and the dry and wet grinding) are schematically demonstrated in Fig. 8 . The comparison between simulated and experimental results is performed under these cutting conditions, and the high similarity between them can be achieved as shown in Fig. 8. In general, the relative difference of the simulated and experimental single-grain grinding forces is $1-15 \%$ in the grinding process of Ti-64 alloy. In other words, cutting force errors of less than $15 \%$ can be attained with this grinding simulation model.

\subsubsection{Grinding temperature}

Fig. 9 presents the simulation of temperature distribution in the grinding zone. The cutting simulation is conducted with the workpiece infeed speed of $3 \mathrm{~m} / \mathrm{min}$ and DOC of $15 \mu \mathrm{m}$ under dry grinding. A set of five checkpoints numbered from 1 to 5 is chosen, as shown in Fig. 9 for a more detailed evaluation of the grinding temperatures throughout the cutting time. The $1^{\text {st }}$ checkpoint is at the top surface of the Ti-64 specimen, and the $5^{\text {th }}$ checkpoint is placed at the depth (about $\left.10 \mu \mathrm{m}\right)$ under the grinding surface. Fig. 10 demonstrates the simulation grinding temperature profile through the five checkpoints. The cutting temperature of the $1^{\text {st }}$ point can be separated into two periods named $\mathrm{P}_{1}$ and $\mathrm{P}_{2}$. In period $\mathrm{P}_{1}$, the grit accesses the checkpoints, and the temperature of this point increases and attains the highest value as the abrasive grit is at the top of the checkpoint. Therefore, the highest temperature at this point (around $358^{\circ} \mathrm{C}$ under the simulation with DOC of $15 \mu \mathrm{m}$ and the workpiece infeed speed of $3 \mathrm{~m} / \mathrm{min}$ ) can be regarded as the temperature of the interaction region between cBN grit and the Ti-64 sample surface. In period $\mathrm{P}_{2}$, when the grit leaves the checkpoint, the temperature of this point is reduced due to thermal conduction, which is described as the dispersion of grinding heat from this zone to the ambient region with lower temperature.

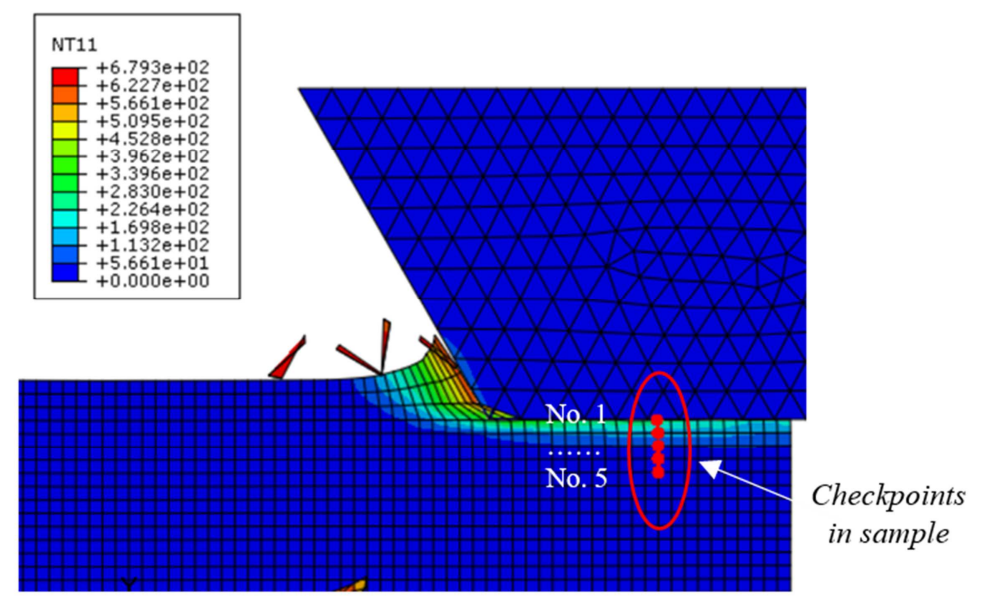

Fig. 9 The simulation of temperature distribution in single-grain grinding 


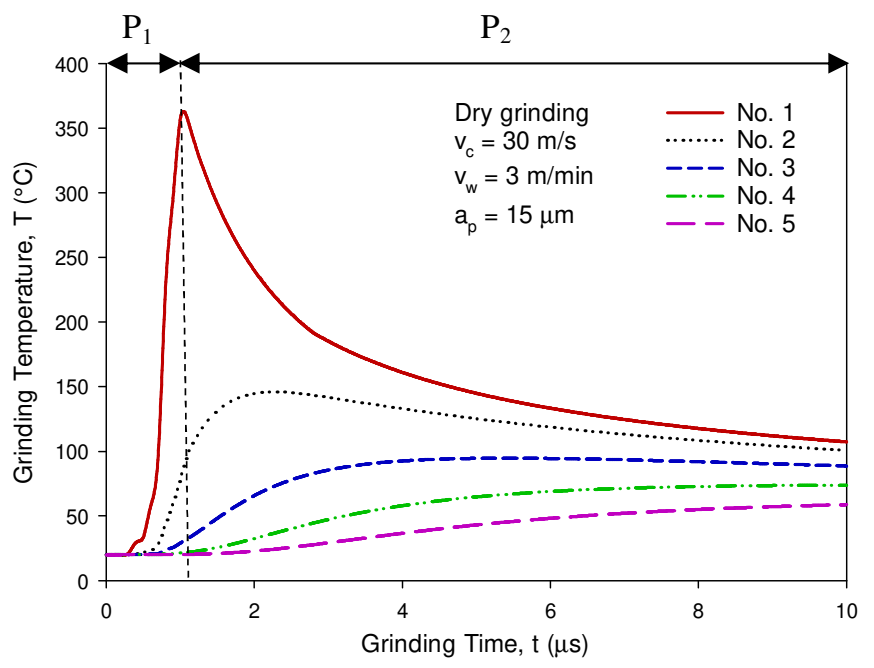

Fig. 10 The temperature profile of five checkpoints

Fig. 11 indicates the simulation grinding temperature on the surface of the Ti-64 sample under various grinding conditions. The higher predicted temperature on the Ti-64 sample surface is found with the increase of DOC. The larger DOC produces the higher $a_{\text {gmax }}$ and expands the tangential grinding force, which creates more thermal energy. Furthermore, the high DOC causes a reduction in the dissipation of heat [22-23]. The increase of workpiece infeed speed leads to a considerable reduction of grinding temperature. The temperature reduction may be the result of the rapid motion of the thermal source and fast deformation on the sample surface [24]. The simulation results of grinding temperature are quite consistent with the experimental ones in the study of Wang [25]. When $a_{\text {gmax }} / 2$ approximates to $4 \mu \mathrm{m}$ (with the cutting condition of $v_{w}=3000$ $\mathrm{mm} / \mathrm{min}$ and $a_{p}=0.005 \mathrm{~mm}$ ), the highest temperatures of the workpiece surface in simulation and experiment are consecutively 325 và $370^{\circ} \mathrm{C}$ (relative error of $13.8 \%$ ). The evaluation of grinding force and temperature may not be very precise as it is difficult to match the material properties with grinding conditions.

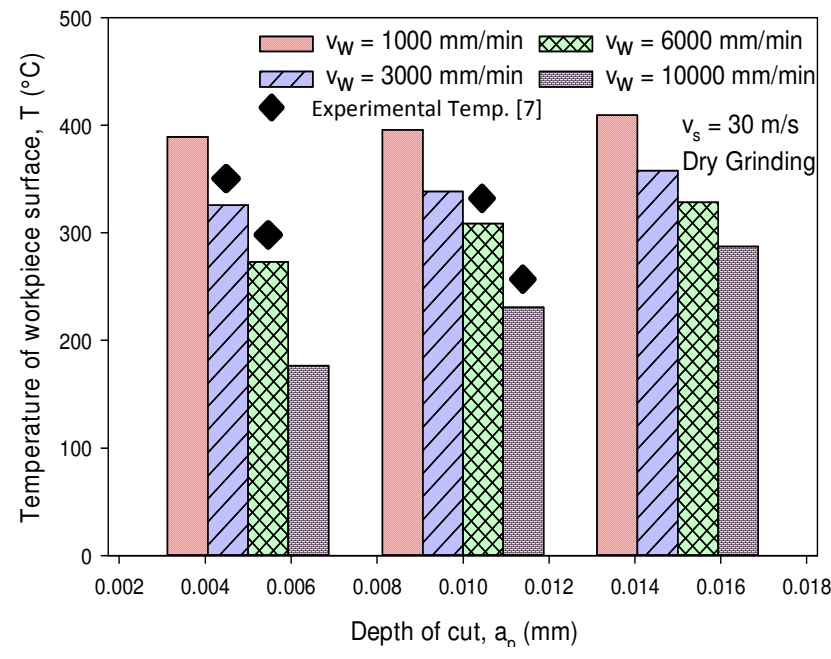

(a) The cutting temperatures vs. DOC

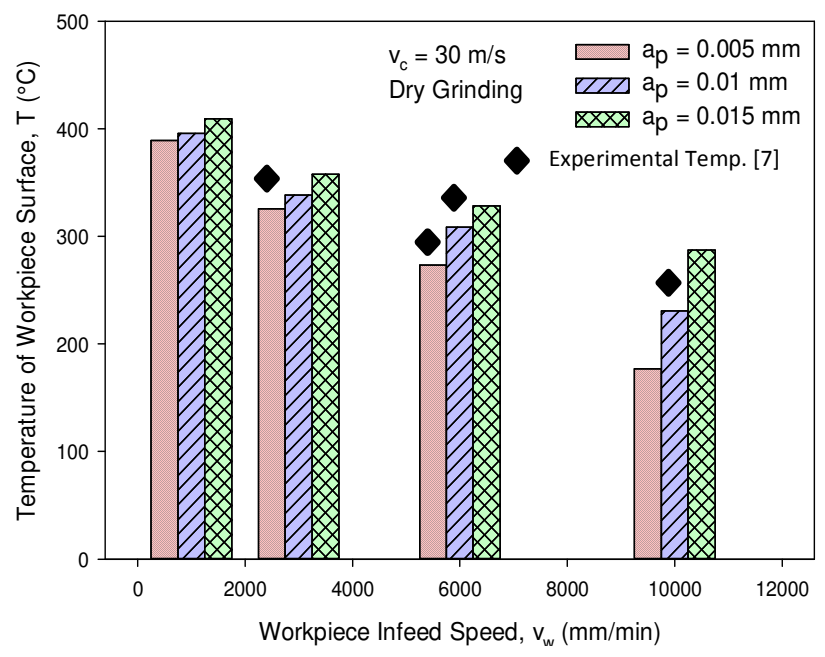

(b) The cutting temperatures vs. workpiece infeed speed

Fig. 11 The effect of grinding conditions on grinding temperature through FEM

\section{Conclusions}

The experimental study of the grinding forces was performed on the Ti-6Al-4V alloy with a cBN grinding wheel under various cutting modes (DOC, workpiece infeed speed, and cooling condition). The grinding forces and temperature in the surface grinding of a single grit were also investigated using ABAQUS/Explicit software as well. The following conclusions could be drawn: 
(1) The normal force values showed about 3 times larger than the tangential ones. The high DOC or workpiece infeed speed generally showed the larger cutting force components. The effect of workpiece infeed speed to cutting forces was more significant than that of DOC. The force ratios at the feed rate of $10 \mathrm{~m} / \mathrm{min}$ were relatively high compared to those under other tested feed rates.

(2) The grinding process using synthetic oil fluid generally exhibited a little lower tangential force than dry cutting conditions, while a slightly lower normal force was found with dry grinding. The force ratio in wet grinding was lower than in dry cutting.

(3) The grinding specific energy of Ti-64 using a cBN wheel varied from 40 to $367 \mathrm{~J} / \mathrm{mm}^{3}$. The grinding energy quickly reduced with the increase of the maximum undeformed chip thickness, $a_{\text {gmax }}$, and thereafter slowly decreased for all the cooling environments. The reduction of specific energy occurred with a larger cross-section area of the cutting layer. The synthetic oil-based cooling provided a slight reduction of grinding energy in comparison with dry grinding.

(4) The simulation cutting temperature on the Ti-64 sample surface increased with a higher DOC value. The increase of workpiece infeed speed led to a significant reduction of grinding temperature. The simulated temperature results were quite consistent with experimental values in other studies. The relative difference between simulated and experimental grinding force was less than $15 \%$, which was admissible. Thereby the grinding temperature could be efficiently forecasted by using the proposed FEM model.

\section{Conflicts of Interest}

The authors declare no conflict of interest.

\section{Acknowledgments}

This study is conducted with financial support from the Hanoi University of Science and Technology (HUST) under project number T2020-PC-205. The School of Mechanical Engineering at HUST is also gratefully acknowledged for providing guidance and expertise.

\section{References}

[1] M. Mukhopadhyay and P. K. Kundu, "Performance Evaluation of Conventional Abrasive Wheels for Grinding Ti-6Al-4V,” IOP Conference Series: Materials Science and Engineering, July 2018, pp. 1-6.

[2] S. Shen, B. Li, and W. Guo, "Surface Integrity in Grinding of C-250 Maraging Steel with Resin-Bonded and Electroplated CBN Grinding Wheels," International Journal of Advanced Manufacturing Technology, vol. 103, no. 1-4, pp. 1079-1094, March 2019.

[3] Z. Chen, H. Qi, B. Zhao, Y. Zhou, L. Shi, H. N. Li, and W. Ding, "On the Tribology and Grinding Performance of Graphene-Modifed Porous Composite-bonded CBN Wheel," Ceramics International, vol. 47, no. 3, pp. 3259-3266, February 2021.

[4] Q. Li, K. Ding, W. Lei, J. Chen, Q. He, and Z. Chen, "Investigation on Induction Brazing of Profiled cBN Wheel for Grinding of Ti-6Al-4V," Chinese Journal of Aeronautics, vol. 34, no. 4, pp. 132-139, July 2020.

[5] A. Naskar, A. Choudhary, and S. Paul, "Wear Mechanism in High-Speed Superabrasive Grinding of Titanium Alloy and Its Effect on Surface Integrity," Wear, vol. 462-463, pp. 1-13, December 2020.

[6] B. Zhao, W. Ding, Y. Zhou, H. Su, and J. Xu, "Effect of Grain Wear on Material Removal Behaviour during Grinding of Ti-6Al-4V Titanium Alloy with Single Aggregated cBN Grain,” Ceramics International, vol. 45, no. 12, pp. 14842-14850, August 2019.

[7] P. Yadav and D. B. Lee, "Oxidation of Titanium and Ti/ (TiB+TiC) Composite," Advances in Technology Innovation, vol. 2, no. 4, pp. 130-132, October 2017. 
[8] Z. Li, W. Ding, C. Liu, and H. Su, "Prediction of Grinding Temperature of PTMCs Based on the Varied Coefficients of Friction in Conventional-Speed and High-Speed Surface Grinding," International Journal of Advanced Manufacturing Technology, vol. 90, no. 5-8, pp. 2335-2344, May 2017.

[9] D. Handa, S. Kumar, S. B. T. Surendran, and V. S. Sooraj, "Simulation of Intermittent Grinding for Ti-6Al-4V with Segmented Wheel," Materials Today: Proceedings, in press.

[10] K. Song, G. Xiao, S. Chen, and S. Li, "Analysis of Thermal-Mechanical Causes of Abrasive Belt Grinding for Titanium Alloy," The International Journal of Advanced Manufacturing Technology, in press.

[11] H. Yun, L. Shuai, X. Guijian, H. Yi, W. Wenxi, and D. Wentao, "Prediction of Surface Residual Stress on Titanium Alloy Generated by Belt Grinding Using Molecular System Dynamics,” Procedia CIRP, vol. 87, pp. 480-484, 2020.

[12] C. Liu, W. Ding, T. Yu, and C. Yang, "Materials Removal Mechanism in High-Speed Grinding of Particulate Reinforced Titanium Matrix Composites,” Precision Engineering, vol. 51, pp. 68-77, January 2018.

[13] V. Malik, N. K. Sanjeev, and P. Bajakke, "Review on Modelling of Friction Stir Welding Using Finite Element Approach and Significance of Formulations in Simulation,” International Journal of Manufacturing Research, vol. 15, no. 2, pp. 107-135, March 2020.

[14] S. Malkin and C. Guo, Grinding Technology: Theory and Applications of Machining with Abrasives, 2nd ed. New York: Industrial Press, 2008.

[15] H. Zhou, W. Ding, and C. Liu, "Material Removal Mechanism of PTMCs in High-Speed Grinding When Considering Consecutive Action of Two Abrasive Grains,” International Journal of Advanced Manufacturing Technology, vol. 100 , no. 1-4, pp. 153-165, January 2019.

[16] D. Fu, W. Ding, Q. Miao, and J. Xu, "Simulation Research on the Grinding Forces and Stresses Distribution in Single-Grain Surface Grinding of Ti-6Al-4V Alloy When Considering the Actual Cutting-Depth Variation," International Journal of Advanced Manufacturing Technology, vol. 91, no. 9, pp. 3591-3602, August 2017.

[17] S. Paul, A. K. Singh, and A. Ghosh, "Grinding of Ti-6Al-4V Under Small Quantity Cooling Lubrication Environment Using Alumina and MWCNT Nanofluids," Materials and Manufacturing Processes, vol. 32, no. 6, pp. 608-615, November 2016.

[18] Z. Li, W. Ding, C. Liu, and H. Zhou, "Grinding Performance of TiCp/Ti-6Al-4V Composites with CBN Wheels, Part I: Experimental Investigation and Surface Features,” Procedia CIRP, vol. 77, pp. 525-528, January 2018.

[19] R. L. Virdi, S. S. Chatha, and H. Singh, "Performance Evaluation of Inconel 718 Under Vegetable Oils Based Nanofluids Using Minimum Quantity Lubrication Grinding," Materials Today: Proceedings, vol. 33, no. 3, pp. 1538-1545, April 2020.

[20] G. Guo, Z. Liu, X. Zheng, and M. Chen, "Investigation on Surface Grinding of Ti-6Al-4V Using Minimum Quantity Lubrication,” Advanced Materials Research, vol. 500, pp. 308-313, April 2012.

[21] W. Kacalak, D. Lipiński, B. Bałasz, Ł. Rypina, K. Tandecka, and F. Szafraniec, "Performance Evaluation of the Grinding Wheel with Aggregates of Grains in Grinding of Ti-6Al-4V Titanium Alloy," International Journal of Advanced Manufacturing Technology, vol. 94, no. 1-4, pp. 301-314, January 2018.

[22] A. Kundu, M. Mukhopadhyay, S. Mahata, A. Banerjee, B. Mandal, and S. Das, "Grinding Titanium Grade 1 Alloy with an Alumina Wheel Using Soap Water," Procedia Manufacturing, vol. 20, pp. 338-343, 2018.

[23] N. Qian, W. Ding, and Y. Zhu, "Comparative Investigation on Grindability of K4125 and Inconel 718 Nickel-Based Superalloys,” International Journal of Advanced Manufacturing Technology, vol. 97, no. 5-8, pp. 1649-1661, April 2018.

[24] Y. Zhang, B. Li, J. Yang, and S. Liang, "Modeling and Optimization of Alloy Steel 20CrMnTi Grinding Process Parameters Based on Experiment Investigation,” International Journal of Advanced Manufacturing Technology, vol. 95, no. 5, pp. 1859-1873, March 2018.

[25] X. Wang, T. Yu, X. Sun, Y. Shi, and W. Wang, "Study of 3D Grinding Temperature Field Based on Finite Difference Method: Considering Machining Parameters and Energy Partition," International Journal of Advanced Manufacturing Technology, vol. 84, no. 5-8, pp. 915-927, May 2016.

Copyright $@$ by the authors. Licensee TAETI, Taiwan. This article is an open access article distributed under the terms and conditions of the Creative Commons Attribution (CC BY-NC) license (https://creativecommons.org/licenses/by-nc/4.0/). 